\title{
Health-Related Quality of Life and Utility Scores of Lung Cancer Patients Treated with Traditional Chinese Medicine in China
}

\author{
Liu Liu ${ }^{1,2}$, Yan Wei ${ }^{1,2}$, Yue Teng $\mathbb{D}^{1-3}$, Juntao Yan $\mathbb{D}^{1,2}$, Fuming $\mathrm{Li}^{1,2}$, Yingyao Chen ${ }^{1,2}$ \\ 'School of Public Health, Fudan University, Shanghai, People's Republic of China; ${ }^{2}$ NHC Key Laboratory of Health Technology Assessment, Fudan \\ University, Shanghai, People's Republic of China; ${ }^{3}$ Department of Outpatient, Shanghai Research Institute of Acupuncture and Meridian, Yueyang \\ Hospital of Integrated Traditional Chinese and Western Medicine, Shanghai University of Traditional Chinese Medicine, Shanghai, People's Republic of \\ China
}

Correspondence: Yan Wei, NHC Key Laboratory of Health Technology Assessment, School of Public Health, Fudan University, Shanghai, People's Republic of China, Tel +86 I8930749707, Email yanwei@fudan.edu.cn

Purpose: To assess health-related quality of life (HRQoL) and utility scores of lung cancer patients treated with traditional Chinese medicine (TCM) in China.

Methods: This cross-sectional study included lung cancer patients treated with TCM in seven tertiary hospitals in Shanghai, China. The HRQoL and utility scores of these patients were measured using the five-level EQ-5D (EQ-5D-5L). The EQ-5D-5L utility scores were derived from the Chinese EQ-5D-5L Value Set. The relationships between HRQoL and the socio-demographic and clinical characteristics of these patients were further explored by Tobit regression.

Results: This study included a total of 347 patients. Their mean \pm SD and median EQ-5D-5L utility scores were $0.851 \pm 0.198$ and 0.893 , respectively. The highest proportion of participants reporting problems was observed in pain/discomfort dimension (57.9\%) and anxiety/depression (45.5\%). Lung cancer patients treated with TCM had poor HRQoL, influenced by cancer clinical stage.

Conclusion: Lung cancer patients treated with TCM have poor HRQoL, with many patients reporting problems in the pain/ discomfort and anxiety/depression dimensions. The information on health utility scores and HRQoL of lung cancer patients treated with TCM could be useful for future supportive care, economic evaluations and decision-making in China.

Keywords: lung cancer, health-related quality of life, traditional Chinese medicine, EQ-5D-5L

\section{Introduction}

Lung cancer is the most commonly diagnosed cancer and the leading cause of cancer deaths, both worldwide ${ }^{1}$ and in China. ${ }^{2}$ In 2015, 787,000 patients in China were newly diagnosed with lung cancer and 631,000 patients died of this disease, accounting for $20.03 \%$ of patients diagnosed with cancer and $26.99 \%$ who died of cancer during that year. ${ }^{3}$ In addition, the burden of lung cancer has increased in the past three decades. Lung cancer is one of the most aggressive malignant tumors, with a 5-year overall survival (OS) rate of about $19.7 \%,{ }^{4}$ much lower than the 5-year OS rate of $40.5 \%$ among all cancer patients in China. ${ }^{3}$ In the treatment process, patients with lung cancers will suffer from the disease's malignant degree and its therapy toxicity. ${ }^{5}$ At present, the leading treatment methods for lung cancer patients include surgery, chemotherapy, radiotherapy, and targeted therapy. Traditional Chinese Medicine (TCM), which has a long history in China, has been widely used to treat various diseases including lung cancer in China and other Asian countries or areas. ${ }^{6-8}$ In addition to their physical symptoms, lung cancer patients frequently experience depression and anxiety, ${ }^{9,10}$ having a negative impact on their health-related quality of life (HRQoL).

HRQoL, especially preference-based health-related QoL, has become an increasingly important outcome measure in the cost-utility analysis (CUA), a particular form of economic evaluation. ${ }^{11}$ HRQoL can inform patient management and policy decisions, making it important to measure HRQoL. ${ }^{12}$ 
Although many studies in patients with lung cancer have investigated their HRQoL after surgery, ${ }^{13}$ radiotherapy, ${ }^{14}$ and/or chemotherapy, ${ }^{15-17}$ few studies to date have evaluated their HRQoL after TCM treatment, which measured by disease-specific instruments, including the Functional Assessment of Cancer Therapy-Lung (FACT-L), ${ }^{18,19}$ the quality-of -life (QoL) instrument for lung cancer based on Traditional Chinese Medicine (QLASTCM-Lu), ${ }^{20,21}$ and European Organization for Research and the Treatment of Cancer Quality of Life Questionnaires (EORTC QLQ-C30 and EORTC QLQ-LC13). ${ }^{22,23}$ Although these methods are valid and reliable, they are not preference-based instruments to elicit health utility scores for lung cancer patients. The present study, therefore, aimed to assess the HRQoL and utility scores in lung cancer patients who received TCM treatment and evaluate the relationships of quality of life outcomes with the sociodemographic and clinical characteristics among lung cancer patients in China.

\section{Materials and Methods Study Design and Setting}

A cross-sectional questionnaire survey was conducted in Shanghai, China. Lung cancer patients treated with TCM were recruited successively from the seven tertiary hospitals of Shanghai in December 2020. All inpatients in the hospital ward who met the inclusion criteria were asked if they would like to participate in the survey. These seven hospitals are regional centers for TCM treatment of lung cancer; therefore, their patients are representative of lung cancer patients treated with TCM. The written informed consent was obtained from all participants prior to the interviews. The study was approved by the Ethics Review Board of the School of Public Health, Fudan University (IRB\# 2020-09-0848), and it adhered to the tenets of the Declaration of Helsinki.

\section{Participants}

Patients diagnosed with lung cancer who were treated with TCM were invited to enroll in this study. Patients were excluded if they were younger than 16 years at the time of the survey, as were those unwilling to provide informed consent, unable to understand the questionnaires or with serious complications.

\section{Data Collection}

The enrolled patients completed the survey questionnaires. The questionnaire consisted of three parts: (1) sociodemographic information; (2) clinical information; and (3) HRQoL instrument. Socio-demographic information included sex, age, level of education, employment status, medical insurance and annual household income. The clinical information included type and severity of lung cancer and the duration since diagnosis. HRQoL was evaluated using the validated Chinese version of EQ-5D-5L.

\section{EQ-5D-5L}

The EQ-5D instrument is one of the most widely used generic preference-based HRQoL instruments internationally, and has been validated in patients with cancer. ${ }^{24}$ To reduce the ceiling effects and improve the sensitivity of the three-level version of EQ-5D (EQ-5D-3L) introduced by the EuroQol Group in the 1990s, ${ }^{25}$ the new five-level EQ-5D questionnaire (EQ-5D-5L) was developed in 2011. ${ }^{26}$ It retains the same five dimensions as the EQ-5D-3L (mobility, self-care, usual activities, pain/ discomfort, anxiety/depression), with each dimension having five levels: no problems, slight problems, moderate problems, severe problems, and unable to/extreme problems, resulting in $3125\left(5^{5}\right)$ unique health states. The Chinese version of the EQ5D-5L has been validated. ${ }^{27}$ The health utility values can be derived by the Chinese-specific scoring algorithm of the EQ-5D$5 \mathrm{~L}$ developed by Luo et $\mathrm{al}^{28}{ }^{28}$ which yielded scores ranging from -0.391 to 1.000 , with zero representing being dead, 1.000 indicating a state of full health, and negative scores indicating health status worse than death. The other component of EQ5D-5L, the EQ Visual Analogue Scale (EQ-VAS), allowed patients to describe their current overall health on a scale ranging from 0 (the worst health state they can imagine) to 100 (the best health state they can imagine). 


\section{Statistical Analysis}

Patients who supplied complete socio-demographic and clinical information and completed both the EQ-5D and EQ-VAS were included in the analysis. Continuous variables were reported as means and standard deviations (SD); due to the skewed distribution, the non-parametric Mann-Whitney U or Kruskal-Wallis test were applied to examine the differences of EQ-5D-5L health state utility scores among the various subgroups. Because the maximum health state utility score was 1 , which was reported by large percentage of patients, the Tobit model was used to explore the impact of sociodemographic variables (sex, geographical region, age, educational level, employment status, medical insurance and annual household income in 2020) and clinical variables (duration since diagnosis, type and clinical stage of Lung cancer) on utility scores of lung cancer patients. All statistical analyses were performed using Stata version 16.0 (StataCorp LP, College Station, TX, USA).

\section{Results}

\section{Characteristics of the Participants}

The 347 patients with lung cancer included 187 men and 160 women, mean age $64.8 \pm 8.7$ years and an average duration since diagnosis of 27.3 months (Table 1). Of these patients, $82.7 \%$ lived in urban areas, $63.7 \%$ were retired, and $98.8 \%$ had health insurance. Most (58.7\%) reported annual per capita household incomes ranging from 50,000 to 149,999 Chinese yuan (approximately US\$ 7657 to 22,971), whereas 18.5\% reported incomes below 50,000 Chinese yuan (US $\$ 7657$ ). Of these patients, $79.5 \%$ had non-small cell lung cancer (NSCLC) and 7.5\% had small cell lung cancer, with $26.4 \%, 14.0 \%, 19.2 \%$, and $40.4 \%$ having stages I-IV lung cancer, respectively.

\section{EQ-5D-5L Dimensions}

The proportion of patients reporting problems in each dimension of the EQ-5D-5L is shown in Table 2 and Figure 1. Problems in the pain/discomfort dimension were reported by $57.9 \%$ of these patients, followed by problems in the anxiety/depression (45.5\%), usual activities (34.0\%), mobility (33.7\%), and self-care (21.9\%) dimensions. A total of 94 patients $(27.1 \%)$ reported no problems in any of the five dimensions.

\section{EQ-5D-5L Utility Scores}

The mean and median of EQ-5D-5L utility scores for patients with lung cancer using the Chinese preference weights were $0.851(S D=0.198)$ and 0.893 respectively (Table 3$)$. The Shapiro-Wilk test statistics suggested that the null hypothesis of normal distribution of EQ-5D-5L utility scores was rejected $(\mathrm{P}<0.001)$. Figure 2 shows the EQ-5D-5L utility scores skewed towards the right higher values.

According to the non-parametric test, the results showed EQ-5D-5L utility scores differed significant among patients living in urban, rural and other areas $(\mathrm{P}<0.05)$. Those who were at III or IV stage of lung cancer had lower utility scores compared with the patients being at I stage $(\mathrm{p}<0.05)$. In addition, utility scores tended to differ between employed and retired patients, as well as in patients treated according to different decision-making models and with different types of health-care insurance $(\mathrm{P}<0.1$ each) (Table 3).

\section{Factors Associated with Health Utility Scores}

The results of Tobit regression analysis are presented in Table 4. The EQ-5D utility scores were significantly lower in women than in men $(\mathrm{P}=0.026)$. Lower utility scores were associated with stage III $(\mathrm{P}=0.036)$ or IV $(\mathrm{P}=0.005)$ cancer at diagnosis. Time since diagnosis of 13-24 months was a significant predictor of low EQ-5D-5L utility scores $(\mathrm{P}=0.013)$. The residence was also significantly predicted utility scores after controlling for other factors.

\section{Discussion}

To our knowledge, this study is the first to report the EQ-5D-5L utility scores and HRQoL of lung cancer patients treated with TCM in China. These findings may be applicable to health economic evaluations of clinical and resource allocations for lung cancer within the health-care sector. 
Table I Socio-Demographic and Clinical Characteristics of Patients with Lung Cancer

\begin{tabular}{|c|c|}
\hline \multirow{2}{*}{ Characteristic } & $\mathbf{N}(\%)$ \\
\hline & $347(100)$ \\
\hline \multicolumn{2}{|l|}{ Sex } \\
\hline Male & $187(53.9)$ \\
\hline Female & $160(46.1)$ \\
\hline \multicolumn{2}{|l|}{ Age (years) } \\
\hline$<60$ & $89(25.7)$ \\
\hline $60-69$ & $150(43.2)$ \\
\hline$>69$ & $108(31.1)$ \\
\hline \multicolumn{2}{|l|}{ Residence } \\
\hline Rural area & $53(15.3)$ \\
\hline Urban area & $287(82.7)$ \\
\hline Other & $7(2.0)$ \\
\hline \multicolumn{2}{|l|}{ Education level $^{\mathrm{a}}$} \\
\hline Primary school or lower & $32(9.3)$ \\
\hline Secondary school & $122(35.4)$ \\
\hline High school or technical secondary school & $124(35.9)$ \\
\hline University degree and above & $67(19.4)$ \\
\hline \multicolumn{2}{|l|}{ Employment status } \\
\hline Employment & $126(36.3)$ \\
\hline Retirement & $221(63.7)$ \\
\hline \multicolumn{2}{|c|}{ Annual household income per capita in 2020 , Chinese yuan ${ }^{b}$} \\
\hline$<50,000$ & $64(18.5)$ \\
\hline $50,000-99,999$ & $113(32.7)$ \\
\hline $100,000-149,999$ & $90(26.0)$ \\
\hline$\geq 150,000$ & $79(22.8)$ \\
\hline \multicolumn{2}{|l|}{ Decision-making model } \\
\hline Shared decision-making & $315(90.8)$ \\
\hline Other & $32(9.2)$ \\
\hline \multicolumn{2}{|l|}{ Health-care insurance } \\
\hline No insurance & $4(1.2)$ \\
\hline Urban employee basic medical insurance & $187(53.9)$ \\
\hline Urban and rural resident basic medical insurance & $59(17.0)$ \\
\hline Other insurance & $97(28.0)$ \\
\hline \multicolumn{2}{|l|}{ Duration of disease since diagnosis (month) } \\
\hline$<8$ & $76(21.9)$ \\
\hline $8-12$ & $71(20.5)$ \\
\hline $13-24$ & $79(22.8)$ \\
\hline$>24$ & $|2|(34.9)$ \\
\hline \multicolumn{2}{|l|}{ Clinical stage ${ }^{c}$} \\
\hline I & $91(26.4)$ \\
\hline II & $48(14.0)$ \\
\hline III & $66(19.2)$ \\
\hline IV & $139(40.4)$ \\
\hline \multicolumn{2}{|l|}{ Type of lung cancer } \\
\hline Non-small cell lung cancer (NSCLC) & $276(79.5)$ \\
\hline Small cell lung cancer (SCLC) & $26(7.5)$ \\
\hline Other & $45(13.0)$ \\
\hline
\end{tabular}

Notes: ${ }^{a}$ Level of education missing for two patients; ${ }^{\mathrm{b}}$ per capita annual household income missing for one patient; 'clinical stage missing for three patients. 
Table 2 Frequency of Item Response in Each EQ-5D-5L Dimension Reported by Participants

\begin{tabular}{|l|c|r|r|r|r|}
\hline Dimensions & $\begin{array}{c}\text { No Problem } \\
\text { N (\%) }\end{array}$ & $\begin{array}{c}\text { Slight Problem } \\
\text { N (\%) }\end{array}$ & $\begin{array}{c}\text { Moderate Problem } \\
\text { N (\%) }\end{array}$ & $\begin{array}{c}\text { Severe Problem } \\
\text { N (\%) }\end{array}$ & $\begin{array}{c}\text { Extreme Problem } \\
\text { N (\%) }\end{array}$ \\
\hline Mobility & $230(66.3)$ & $89(25.6)$ & $18(5.2)$ & $7(2.0)$ & $3(0.9)$ \\
Self-care & $271(78.1)$ & $54(15.6)$ & $16(4.6)$ & $4(1.2)$ & $2(0.6)$ \\
Usual activities & $229(66.0)$ & $85(24.5)$ & $22(6.3)$ & $8(2.3)$ & $3(0.9)$ \\
Pain/discomfort & $146(42.1)$ & $167(48.1)$ & $19(5.5)$ & $12(3.5)$ & $3(0.9)$ \\
Anxiety/depression & $189(54.5)$ & $136(39.2)$ & $20(5.8)$ & $2(0.6)$ & $0(0.0)$ \\
\hline
\end{tabular}

The mean health state utility score, as determined by the EQ-5D-5L, in these patients was 0.851 , lower than those reported in urban Chinese population $(0.957)^{29}$ and in urban and rural residents in four cities in China $(0.951),{ }^{30}$ but equivalent to that of patients with non-small cell lung cancer in Taiwan of China. ${ }^{31}$ Before our study, a cross-sectional study of advanced non-small-cell lung cancer patients in a hospital in China found that their mean health utility score was 0.814, somewhat lower than in our patient populations. ${ }^{32}$ In comparison, patients with advanced lung cancer in France and Germany were found to have a mean EQ-5D-3L index score of $0.58,{ }^{33}$ and patients with lung cancer in Canada also had a lower mean EQ-5D index score. ${ }^{34}$

The differences among these scores may be due to differences among treatment types and clinical stage. Previous studies examined the HRQoL of patients with advanced lung cancer who received drug treatment, including targeted and chemotherapeutic agents. In contrast, the patients in the present study were recruited at tertiary hospitals, were at all stages of disease, and tended to be treated with TCM. The adverse effects of targeted drugs and chemotherapeutic agents may result in chronicity and a decrease in health utility, ${ }^{35}$ whereas, TCM is thought to reduce chemotherapy-related side effects and improve HRQoL. ${ }^{36}$ In addition, previous studies in lung cancer measured health status values using the EQ5D-3L which has a higher ceiling effect and lower discriminatory power than the EQ-5D-5L. ${ }^{29}$

In this study, pain/discomfort (57.9\%) and anxiety/depression (45.5\%) were the problems most frequently reported by respondents, similar to previous findings Chinese patients with advanced lung cancer. ${ }^{32,37}$ Lung cancer therefore had a significant effect on the physiological and psychological status of these patients. Pain has been reported to be an inevitable symptom in lung cancer patients and the main physical symptom causing psychological problems in elderly

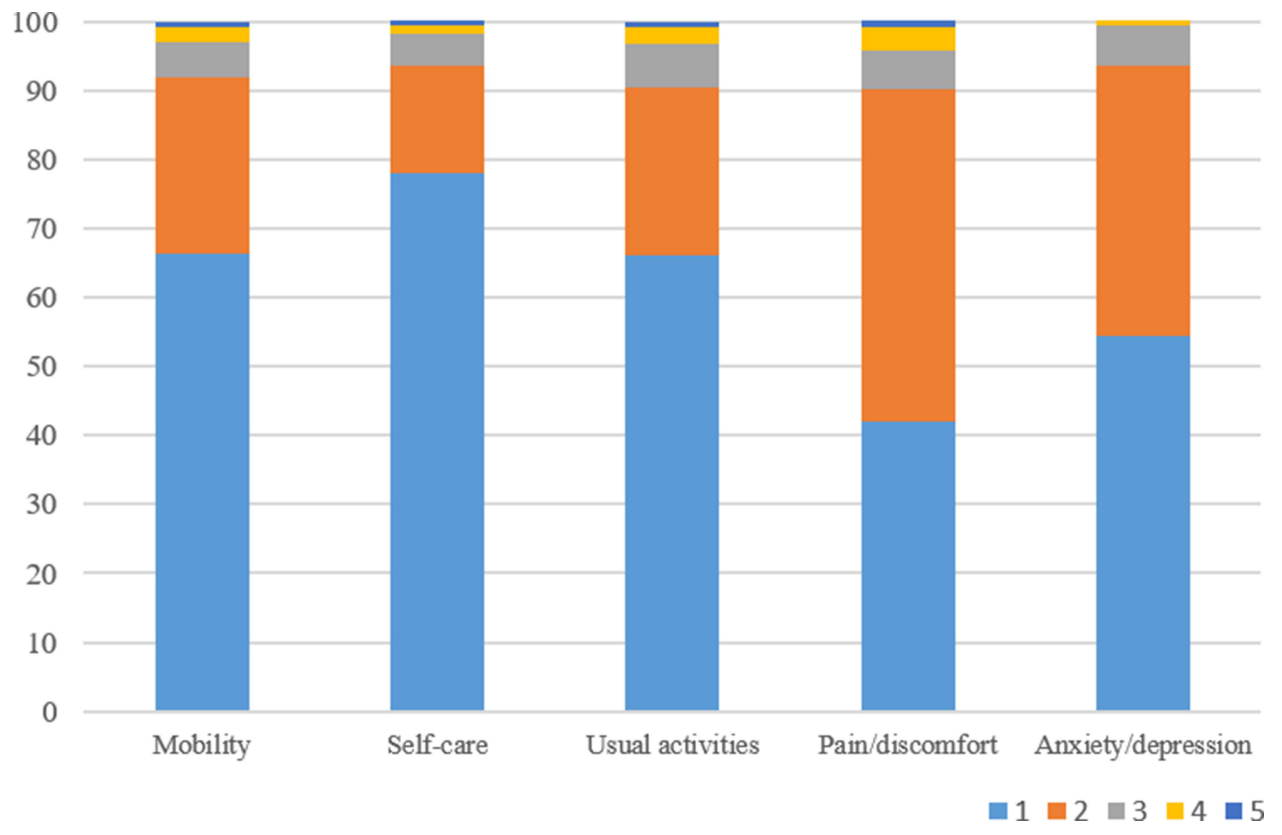

Figure I Patients reporting problems percentage in five levels of EQ-5D. 
Table 3 EQ-5D-5L Utility Scores of Participants with Lung Cancer in Different Characteristics

\begin{tabular}{|c|c|c|c|c|c|}
\hline & Range & Mean & SD & Median & $P$ values \\
\hline Sex & & & & & 0.216 \\
\hline Male & $-0.200-1.000$ & 0.850 & 0.214 & 0.897 & \\
\hline Female & $-0.190-1.000$ & 0.853 & 0.178 & 0.893 & \\
\hline Age (years) & & & & & 0.817 \\
\hline$<60$ & $-0.190-1.000$ & 0.864 & 0.190 & 0.893 & \\
\hline $60-69$ & $-0.160-1.000$ & 0.849 & 0.203 & 0.893 & \\
\hline$>69$ & $-0.200-1.000$ & 0.844 & 0.198 & 0.893 & \\
\hline Residence & & & & & 0.014 \\
\hline Rural area & $0.360-1.000$ & 0.881 & 0.136 & 0.906 & \\
\hline Urban area & $-0.200-1.000$ & 0.853 & 0.197 & 0.893 & \\
\hline Other & $-0.160-0.940$ & 0.562 & 0.385 & 0.702 & \\
\hline Education level & & & & & 0.549 \\
\hline Primary school or lower & $0.450-1.000$ & 0.848 & 0.171 & 0.918 & \\
\hline Secondary school & $-0.190-1.000$ & 0.844 & 0.196 & 0.893 & \\
\hline High school or technical secondary school & $-0.160-1.000$ & 0.856 & 0.200 & 0.902 & \\
\hline University degree and above & $-0.200-1.000$ & 0.864 & 0.210 & 0.897 & \\
\hline Employment status & & & & & 0.066 \\
\hline Employment & $-0.160-1.000$ & 0.873 & 0.183 & 0.942 & \\
\hline Retirement & $-0.200-1.000$ & 0.839 & 0.205 & 0.893 & \\
\hline $\begin{array}{l}\text { Annual household income per capita in 2020, Chinese } \\
\text { yuan }\end{array}$ & & & & & 0.113 \\
\hline$<50,000$ & $0.260-1.000$ & 0.855 & 0.169 & 0.893 & \\
\hline $50,000-99,999$ & $-0.200-1.000$ & 0.825 & 0.218 & 0.893 & \\
\hline $100,000-149,999$ & $-0.190-1.000$ & 0.868 & 0.218 & 0.942 & \\
\hline$\geq 150,000$ & $0.030-1.000$ & 0.868 & 0.163 & 0.893 & \\
\hline Decision-making model & & & & & 0.080 \\
\hline Shared decision-making & $-0.200-1.000$ & 0.852 & 0.204 & 0.897 & \\
\hline Other & $0.470-1.000$ & $0.84 I$ & 0.130 & 0.862 & \\
\hline Health-care insurance & & & & & 0.064 \\
\hline No insurance & $-0.750-0.940$ & 0.864 & 0.095 & 0.883 & \\
\hline Urban employee basic medical insurance & $-0.190-1.000$ & 0.861 & 0.208 & 0.934 & \\
\hline Urban and rural resident basic medical insurance & $0.430-1.000$ & 0.836 & 0.146 & 0.848 & \\
\hline Other insurance & $-0.200-1.000$ & $0.84 I$ & 0.211 & 0.893 & \\
\hline Duration of disease since diagnosis (month) & & & & & 0.738 \\
\hline$<8$ & $-0.160-1.000$ & 0.867 & 0.181 & 0.900 & \\
\hline $8-12$ & $-0.190-1.000$ & 0.857 & 0.200 & 0.888 & \\
\hline $13-24$ & $-0.200-1.000$ & 0.810 & 0.258 & 0.893 & \\
\hline$>24$ & $0.030-1.000$ & 0.864 & 0.157 & 0.893 & \\
\hline Clinical stage & & & & & 0.013 \\
\hline I & $0.200-1.000$ & 0.886 & 0.144 & 0.906 & \\
\hline ॥ & $-0.120-1.000$ & 0.889 & 0.181 & 0.942 & \\
\hline III & $-0.160-1.000$ & 0.842 & 0.224 & 0.893 & \\
\hline IV & $-0.200-1.000$ & 0.819 & 0.218 & 0.893 & \\
\hline Type of lung cancer & & & & & 0.145 \\
\hline Non-small cell lung cancers (NSCLC) & $-0.200-1.000$ & 0.860 & 0.193 & 0.895 & \\
\hline Small cell lung cancers (SCLC) & $-0.016-1.000$ & 0.765 & 0.282 & 0.848 & \\
\hline Other & $0.200-1.000$ & 0.848 & 0.154 & 0.893 & \\
\hline Total & $-0.200-1.000$ & 0.851 & 0.198 & 0.893 & \\
\hline
\end{tabular}

Abbreviation: SD, standard deviation. 


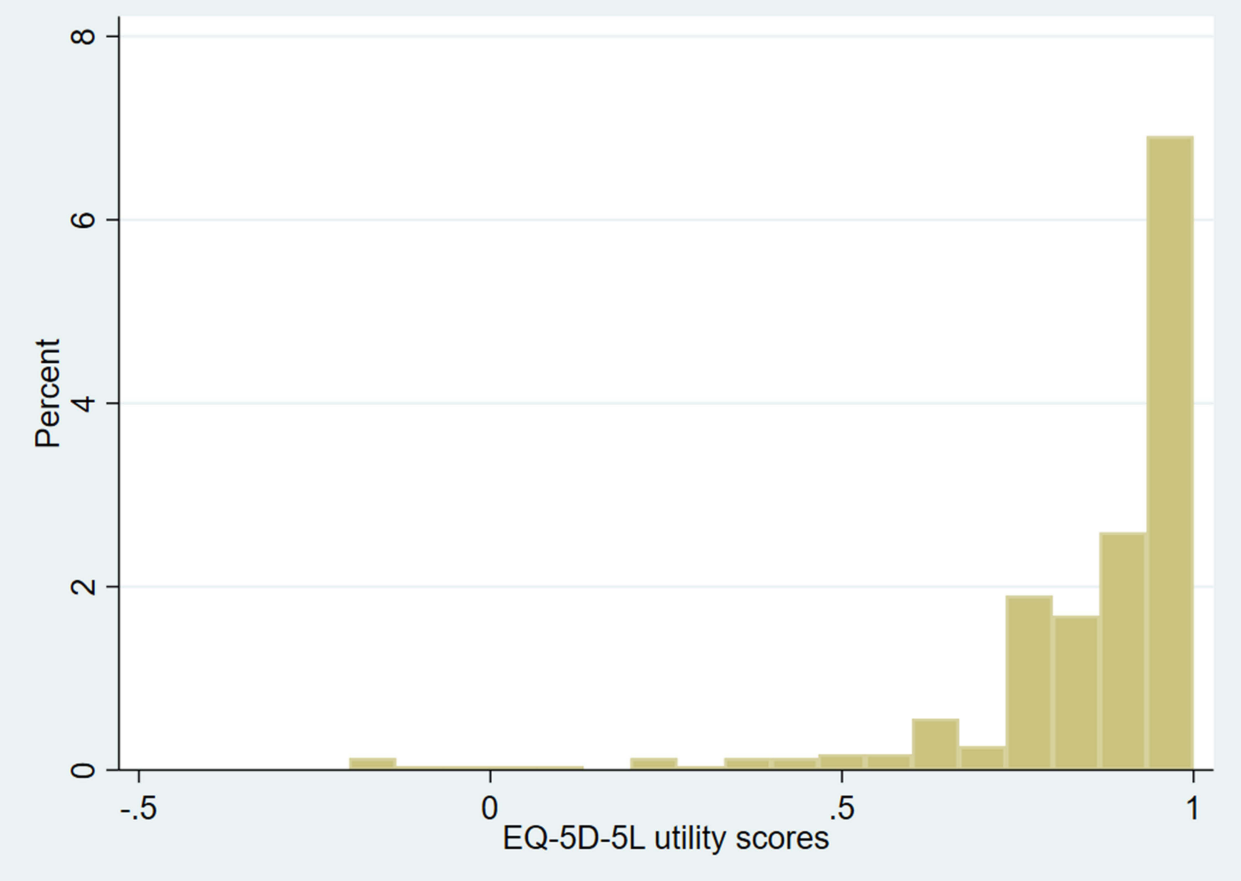

Figure 2 Distribution of EQ-5D-5L utility scores among lung cancer patients.

lung cancer patients. ${ }^{38}$ A more severe degree of pain is associated with the aggravation of patients' anxiety, depression and other negative psychological emotions. ${ }^{39}$ Efforts are therefore needed to alleviate pain/discomfort and anxiety/ depression during the treatment of lung cancer.

The present results showed three independent factors influenced the HRQoL of lung cancer patients: sex, tumor clinical stage, and residence. Women exhibited lower utility than men, in agreement with previous studies in China ${ }^{40,41}$ and Japan. ${ }^{42}$ HRQoL tended to decrease in patients with more advanced clinical stage, consistent with previous reports on patients with lung cancer in China, ${ }^{32}$ France and Germany ${ }^{33}$ and in patients with other types of cancer. ${ }^{43}$ Patients with advanced stage cancers have more obvious physical symptoms related to the disease, and the difficulty of treatment may lead to poor prognosis or death, ${ }^{38}$ increasing anxiety and depression and worsening quality of life. Our results showed that residential disparities influenced the HRQoL of patients, consistent with findings previously reported in China. ${ }^{44}$

This study had several limitations. First, the study population consisted of lung cancer patients from several tertiary hospitals in Shanghai, China, which may not be representative of all lung cancer patients in mainland China. However, the study population included patients at different stages of lung cancer. Second, this study was cross-sectional survey in design, and therefore could not determine the causal relationships between HRQoL and other influencing factors. These causal relationships should be examined in future longitudinal studies. In addition, we only pay attention to whether the patient has received TCM, and not whether the patient has received other treatments at the same time, which may have a certain impact on the results. Although additional studies are required, the results of this study may provide information on HRQoL on Chinese lung cancer patients receiving TCM treatment.

\section{Conclusion}

This study found that lung cancer patients treated with TCM had a low health state utility and poor HRQoL. The dimensions of reduced HRQoL most frequently reported by patients were pain/discomfort and anxiety/depression. More advanced stage tumors were associated with lower HRQoL. These results can provide basic information on health utility scores and HRQoL of lung cancer patients treated with TCM for future supportive care, economic evaluations and decision-making in China. In addition, the HRQoL of lung cancer patients may be improved by reducing pain and depression during the process of treatment. 
Table 4 Factors Influencing EQ-5D-5L Utility Scores as Determined by a Tobit Regression Model

\begin{tabular}{|c|c|c|c|}
\hline & Coefficients & SE & $P$ values \\
\hline \multicolumn{4}{|l|}{ Sex } \\
\hline Male & Ref & & \\
\hline Female & -0.067 & 0.030 & 0.026 \\
\hline \multicolumn{4}{|l|}{ Age (years) } \\
\hline$<60$ & Ref & & \\
\hline $60-69$ & -0.006 & 0.034 & 0.851 \\
\hline$>69$ & -0.033 & 0.038 & 0.387 \\
\hline \multicolumn{4}{|l|}{ Residence } \\
\hline Other & Ref & & \\
\hline Rural area & 0.536 & 0.117 & $<0.001$ \\
\hline Urban area & 0.485 & 0.112 & $<0.001$ \\
\hline \multicolumn{4}{|l|}{ Education level } \\
\hline Primary school or lower & Ref & & \\
\hline Secondary school & -0.064 & 0.053 & 0.223 \\
\hline High school or technical secondary school & -0.045 & 0.054 & 0.405 \\
\hline University degree and above & -0.057 & 0.060 & 0.342 \\
\hline \multicolumn{4}{|l|}{ Employment status } \\
\hline Employment & Ref & & \\
\hline Retirement & -0.045 & 0.030 & 0.137 \\
\hline \multicolumn{4}{|c|}{ Annual household income per capita in 2020 , Chinese yuan } \\
\hline$<50,000$ & Ref & & \\
\hline $50,000-99,999$ & -0.036 & 0.040 & 0.363 \\
\hline $100,000-149,999$ & 0.032 & 0.043 & 0.447 \\
\hline$\geq 150,000$ & -0.005 & 0.045 & 0.913 \\
\hline \multicolumn{4}{|l|}{ Decision-making model } \\
\hline Shared decision-making & Ref & & \\
\hline Other & -0.063 & 0.047 & 0.182 \\
\hline \multicolumn{4}{|l|}{ Health-care insurance } \\
\hline No insurance & Ref & & \\
\hline Urban employee basic medical insurance & 0.124 & 0.121 & 0.307 \\
\hline Urban and rural resident basic medical insurance & 0.047 & 0.124 & 0.702 \\
\hline Other insurance & 0.081 & 0.122 & 0.508 \\
\hline \multicolumn{4}{|l|}{ Duration of disease since diagnosis (months) } \\
\hline$<8$ & Ref & & \\
\hline $8-12$ & -0.010 & 0.042 & 0.814 \\
\hline $13-24$ & -0.107 & 0.043 & 0.013 \\
\hline$>24$ & -0.025 & 0.041 & 0.534 \\
\hline \multicolumn{4}{|l|}{ Clinical stage } \\
\hline I & Ref & & \\
\hline II & -0.007 & 0.046 & 0.876 \\
\hline III & -0.091 & 0.043 & 0.036 \\
\hline IV & -0.100 & 0.036 & 0.005 \\
\hline \multicolumn{4}{|l|}{ Type of lung cancer } \\
\hline Other & Ref & & \\
\hline Non-small cell lung cancers (NSCLC) & 0.050 & 0.040 & 0.210 \\
\hline Small cell lung cancers (SCLC) & -0.033 & 0.063 & 0.604 \\
\hline
\end{tabular}

Abbreviation: SE, standard error.

\section{Acknowledgments}

The authors thank all the study participants for their time and effort. 


\section{Funding}

The study was funded by the Ministry of Education of Humanities and Social Science Project (No.18YJCZH187).

\section{Disclosure}

The authors have no conflict of interest to report.

\section{References}

1. Bray F, Ferlay J, Soerjomataram I, Siegel RL, Torre LA, Jemal A. Global cancer statistics 2018: GLOBOCAN estimates of incidence and mortality worldwide for 36 cancers in 185 countries. CA Cancer J Clin. 2018;68(6):394-424. doi:10.3322/caac.21492

2. Zheng RS, Sun KX, Zhang SW, et al. [Report of cancer epidemiology in China, 2015]. Zhonghua Zhong Liu Za Zhi. 2019;41(1):19-28. [Chinese]. doi:10.3760/cma.j.issn.0253-3766.2019.01.005

3. He S, Li H, Cao M, et al. Trends and risk factors of lung cancer in China. Chin J Cancer Res. 2020;32(6):683-694. doi:10.21147/j.issn.10009604.2020.06.02

4. Lu T, Yang X, Huang Y, et al. Trends in the incidence, treatment, and survival of patients with lung cancer in the last four decades. Cancer Manag Res. 2019;11:943-953. doi:10.2147/CMAR.S187317

5. Polanski J, Jankowska-Polanska B, Rosinczuk J, Chabowski M, Szymanska-Chabowska A. Quality of life of patients with lung cancer. Onco Targets Ther. 2016;9:1023-1028. doi:10.2147/OTT.S100685

6. Liao YH, Li CI, Lin CC, Lin JG, Chiang JH, Li TC. Traditional Chinese medicine as adjunctive therapy improves the long-term survival of lung cancer patients. J Cancer Res Clin Oncol. 2017;143(12):2425-2435. doi:10.1007/s00432-017-2491-6

7. Wang Q, Wang Q, Wang SF, et al. Oral Chinese herbal medicine as maintenance treatment after chemotherapy for advanced non-small-cell lung cancer: a systematic review and meta-analysis. Curr Oncol. 2017;24(4):e269-e276. doi:10.3747/co.24.3561

8. Chen S, Bao Y, Xu J, et al. Efficacy and safety of TCM combined with chemotherapy for SCLC: a systematic review and meta-analysis. $J$ Cancer Res Clin Oncol. 2020;146(11):2913-2935. doi:10.1007/s00432-020-03353-0

9. Morrison EJ, Novotny PJ, Sloan JA, et al. Emotional problems, quality of life, and symptom burden in patients with lung cancer. Clin Lung Cancer. 2017;18(5):497-503. doi:10.1016/j.cllc.2017.02.008

10. Rueda JR, Solà I, Pascual A, Subirana Casacuberta M. Non-invasive interventions for improving well-being and quality of life in patients with lung cancer. Cochrane Database Syst Rev. 2011;2011(9):Cd004282.

11. Brazier J, Ratcliffe J, Salomon J, Tsuchiya A. Measuring and Valuing Health Benefits for Economic Evaluation. 2nd ed. Oxford: Oxford University Press; 2016.

12. Guyatt GH, Feeny DH, Patrick DL. Measuring health-related quality of life. Ann Intern Med. 1993;118(8):622-629. doi:10.7326/0003-4819-1188-199304150-00009

13. Poghosyan H, Sheldon LK, Leveille SG, Cooley ME. Health-related quality of life after surgical treatment in patients with non-small cell lung cancer: a systematic review. Lung Cancer. 2013;81(1):11-26. doi:10.1016/j.lungcan.2013.03.013

14. Chen H, Louie AV, Boldt RG, Rodrigues GB, Palma DA, Senan S. Quality of life after stereotactic ablative radiotherapy for early-stage lung cancer: a systematic review. Clin Lung Cancer. 2016;17(5):e141-e149. doi:10.1016/j.cllc.2015.12.009

15. Reale ML, De Luca E, Lombardi P, et al. Quality of life analysis in lung cancer: a systematic review of phase III trials published between 2012 and 2018. Lung Cancer. 2020;139:47-54. doi:10.1016/j.lungcan.2019.10.022

16. Reck M, Brahmer J, Bennett B, et al. Evaluation of health-related quality of life and symptoms in patients with advanced non-squamous non-small cell lung cancer treated with nivolumab or docetaxel in CheckMate 057. Eur J Cancer. 2018;102:23-30. doi:10.1016/j.ejca.2018.05.005

17. Tanvetyanon T, Soares HP, Djulbegovic B, Jacobsen PB, Bepler G. A systematic review of quality of life associated with standard chemotherapy regimens for advanced non-small cell lung cancer. J Thorac Oncol. 2007;2(12):1091-1097. doi:10.1097/JTO.0b013e31815cff64

18. Liu J, Mao JJ, Li SQ, Lin H. Preliminary efficacy and safety of reishi \& privet formula on quality of life among non-small cell lung cancer patients undergoing chemotherapy: a randomized placebo-controlled trial. Integr Cancer Ther. 2020;19:1534735420944491. doi:10.1177/ 1534735420944491

19. Guo H, Liu JX, Li H, Baak JPA. In metastatic non-small cell lung cancer platinum-based treated patients, herbal treatment improves the quality of life. A prospective randomized controlled clinical trial. Front Pharmacol. 2017;8:454. doi:10.3389/fphar.2017.00454

20. Wan C, You S, Quan P, et al. Development and validation of the quality-of-life assessment system for lung cancer based on traditional Chinese medicine. Evid Based Complement Alternat Med. 2012;2012:945910. doi:10.1155/2012/945910

21. Wang TT, He LY, Zhang M, et al. Development of improved version of quality of life assessment instrument for lung cancer patients based on traditional Chinese medicine (QLASTCM-Lu). Chin J Integr Med. 2019;25(11):831-836. doi:10.1007/s11655-018-2991-5

22. Tang WR, Yang SH, Yu CT, et al. Long-term effectiveness of combined treatment with traditional Chinese medicine and Western medicine on the prognosis of patients with lung cancer. J Altern Complement Med. 2016;22(3):212-222. doi:10.1089/acm.2015.0214

23. Xu L, Li H, Xu Z, et al. Multi-center randomized double-blind controlled clinical study of chemotherapy combined with or without traditional Chinese medicine on quality of life of postoperative non-small cell lung cancer patients. BMC Complement Altern Med. 2012;12:112. doi:10.1186/ $1472-6882-12-112$

24. Kim SH, Kim HJ, Lee SI, Jo MW. Comparing the psychometric properties of the EQ-5D-3L and EQ-5D-5L in cancer patients in Korea. Qual Life Res. 2012;21(6):1065-1073. doi:10.1007/s11136-011-0018-1

25. Brooks R. EuroQol: the current state of play. Health Policy. 1996;37(1):53-72. doi:10.1016/0168-8510(96)00822-6

26. Herdman M, Gudex C, Lloyd A, et al. Development and preliminary testing of the new five-level version of EQ-5D (EQ-5D-5L). Qual Life Res. 2011;20(10):1727-1736. doi:10.1007/s11136-011-9903-x

27. Luo N, Li M, Liu GG, Lloyd A, de Charro F, Herdman M. Developing the Chinese version of the new 5-level EQ-5D descriptive system: the response scaling approach. Qual Life Res. 2013;22(4):885-890. doi:10.1007/s11136-012-0200-0 
28. Luo N, Liu G, Li M, Guan H, Jin X, Rand-Hendriksen K. Estimating an EQ-5D-5L value set for China. Value Health. 2017;20(4):662-669. doi:10.1016/j.jval.2016.11.016

29. Yang Z, Busschbach J, Liu G, Luo N. EQ-5D-5L norms for the urban Chinese population in China. Health Qual Life Outcomes. $2018 ; 16(1): 210$. doi:10.1186/s12955-018-1036-2

30. Guan H, Liu G. Comparison analysis on health related quality of life among urban and rural residents in 4 cities of China. Chin Health Econ. 2015;34(2):5-12.

31. Yang SC, Lai WW, Hsu JC, Su WC, Wang JD. Comparative effectiveness and cost-effectiveness of three first-line EGFR-tyrosine kinase inhibitors: analysis of real-world data in a tertiary hospital in Taiwan. PLoS One. 2020;15(4):e0231413. doi:10.1371/journal.pone.0231413

32. Shen Y, Wu B, Wang X, Zhu J. Health state utilities in patients with advanced non-small-cell lung cancer in China. J Comp Eff Res. 2018;7 (5):443-452. doi:10.2217/cer-2017-0069

33. Iyer S, Taylor-Stokes G, Roughley A. Symptom burden and quality of life in advanced non-small cell lung cancer patients in France and Germany. Lung Cancer. 2013;81(2):288-293. doi:10.1016/j.lungcan.2013.03.008

34. Jiang SX, Walton RN, Hueniken K, et al. Real-world health utility scores and toxicities to tyrosine kinase inhibitors in epidermal growth factor receptor mutated advanced non-small cell lung cancer. Cancer Med. 2019;8(18):7542-7555. doi:10.1002/cam4.2603

35. Ko CY, Maggard M, Livingston EH. Evaluating health utility in patients with melanoma, breast cancer, colon cancer, and lung cancer: a nationwide, population-based assessment. J Surg Res. 2003;114(1):1-5. doi:10.1016/S0022-4804(03)00167-7

36. Zhang S, Ni M, Wang K, Wu J, Duan X, Liu S. Shenqifuzheng injection combined with conventional chemotherapy in treatment of non-small cell lung cancer: meta-analysis. Evaluation and Analysis of Drug-Use in Hospitals of China; 2018:1153-1159, 1165.

37. Dong Z, Wang L. [Quality of life in patients with locally advanced of advanced lung cancer evaluated by EQ-5D Chinese-TTO]. J Tongji Univ Med Sci. 2018;39(05):83-87. [Chinese].

38. Zhang S, Ren X, Tian Y. [Investigation on psychological distress status of elderly patients with Iung cancer and analysis of its influencing factors]. Shaanxi Med J. 2021;50(2):245-250. [Chinese].

39. Mou Q, Yu CH, Li JY. [Investigation and analysis for impact factors of distress in patients with first diagnosed lung cancer]. J Peking Univ Health Sci. 2016;48(03):507-514. [Chinese].

40. Wong ELY, Xu RH, Cheung AWL. Health-related quality of life among patients with hypertension: population-based survey using EQ-5D-5L in Hong Kong SAR, China. BMJ Open. 2019;9(9):e032544. doi:10.1136/bmjopen-2019-032544

41. Sun S, Chen J, Johannesson M, et al. Regional differences in health status in China: population health-related quality of life results from the National Health Services Survey 2008. Health Place. 2011;17(2):671-680. doi:10.1016/j.healthplace.2011.01.007

42. Fujikawa A, Suzue T, Jitsunari F, Hirao T. Evaluation of health-related quality of life using EQ-5D in Takamatsu, Japan. Environ Health Prev Med. 2011;16(1):25-35. doi:10.1007/s12199-010-0162-1

43. Huang W, Yang J, Liu Y, et al. Assessing health-related quality of life of patients with colorectal cancer using EQ-5D-5L: a cross-sectional study in Heilongjiang of China. BMJ Open. 2018;8(12):e022711. doi:10.1136/bmjopen-2018-022711

44. Yao Q, Liu C, Zhang Y, Xu L. Population norms for the EQ-5D-3L in China derived from the 2013 National Health Services Survey. $J$ Glob Health. 2021;11:08001. doi:10.7189/jogh.11.08001

\section{Publish your work in this journal}

Patient Preference and Adherence is an international, peer-reviewed, open access journal that focusing on the growing importance of patient preference and adherence throughout the therapeutic continuum. Patient satisfaction, acceptability, quality of life, compliance, persistence and their role in developing new therapeutic modalities and compounds to optimize clinical outcomes for existing disease states are major areas of interest for the journal. This journal has been accepted for indexing on PubMed Central. The manuscript management system is completely online and includes a very quick and fair peer-review system, which is all easy to use. Visit http://www.dovepress.com/testimonials.php to read real quotes from published authors.

Submit your manuscript here: https://www.dovepress.com/patient-preference-and-adherence-journal 